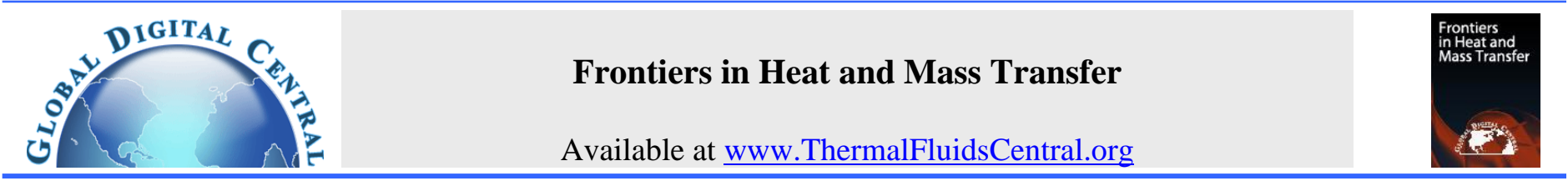

\title{
VARIABLE HEAT SOURCE AND WALL RADIATION EFFECTS ON BOUNDARY LAYER CONVECTION FROM AN INCLINED PLATE IN NON-DARCIAN POROUS MEDIUM
}

\author{
Elyazid Flilihi $^{\mathrm{a}, \dagger}$, Mohammed Sriti $^{\mathrm{a}}$, Driss Achemlal ${ }^{\mathrm{b}}$, Mohamed El haroui $^{\mathrm{a}}$ \\ a Sidi Mohamed Ben Abdellah University, Polydisciplinary Faculty of Taza, Engineering Sciences Laboratory, BP.1223, Taza, Morocco \\ ${ }^{\mathrm{b}}$ Mohammed First University, National School of Applied Sciences - Al Hoceima, Laboratory of Engineering Sciences and Applications, BP.03, Ajdir -
} Al Hoceima, Morocco

\begin{abstract}
A semi - analytical investigation is performed to analyze the thermal convection flow with a radiation flux and a variable internal heat generation along an inclined plate embedded in a saturated porous medium. The flow in the porous medium is modeled with the Darcy-Brinkman law taking into account the convective term, while the temperature field is obtained from the energy equation. These governing equations with the boundary conditions are first cast into a dimensionless form by using a unique similarity transformation and the resulting coupled differential equations are then solved numerically by a computational program based on the fifth order Runge-Kutta scheme with shooting iteration technique. The obtained results are presented in dimensional and dimensionless form. The effects of the main governing parameters, such as permeability, radiation, internal heat generation, inclination angle, Grashof number, Prandtl number, fluid suction on the isothermal lines distributions, the local Nusselt number and the local skin-friction profiles are examined and the physical aspect of the problem is discussed. The comparison with previously published work shows excellent agreement.
\end{abstract}

Keywords: Porous medium, Darcy-Brinkman model, thermal convection, internal heat source, thermal radiation, flat plate.

\section{INTRODUCTION}

Convective flow through porous media is a branch of research undergoing rapid growth in fluid mechanics and heat transfer. This is quite natural because of its important applications in chemical engineering, soil physics, nuclear reactors, oil extraction, transport processes in aquifers and biological systems. The growing volume of work devoted to this area is amply documented in the recent excellent reviews by (Vafai, 2005) and (Nield and Bejan, 2006).

Numerous studies of such flows have been reported in the past several decades using both Darcian and non-Darcian models for the porous medium. The Darcy law which is limited to slow flows. On the other hand, when the Reynolds number is greater than order of unity, or, for high velocity flow situations, Darcy's law is inapplicable because it does not account the effect of solid boundary, inertia forces... These missing effects are very significant in most practical situations such as fluid flow in geothermal reservoirs, separation processes in chemical industries, thermal insulation, petroleum reservoir, and so on. These effects are incorporated by using the general flow known as Brinkman-Forchheimer extended Darcy model. The Brinkman's extension, which includes a viscous shear stress term in the momentum equation, has been used to account for the boundary effects. The inertial effects can be modelled through the addition of a quadratic term in velocity, which is known as
Forchheimer's extension. Therefore, the research interest in recent studies has been focused on the important non-Darcian phenomenon of convective heat transport in porous media.

Many studies have appeared concerning the interaction of radiative flux with thermal convection flows. In view of this, (Hossain and Pop, 1997) have analyzed the radiation effect on a free convection flow along an inclined plate in a porous space. After, Raptis (1998) has considered thermal radiation and free convection in a porous medium. (Chamkha et al., 2002) have investigated the effect of radiation heat transfer on flow and thermal fields from an inclined plate embedded in a variable porosity porous medium due to solar radiation. Furthermore, (Aydin and Kaya, 2008) have studied mixed convection heat transfer about a permeable vertical plate in the presence of magneto and thermal radiation effects. In this work, the problem is resolved numerically using the Keller box scheme. The obtained results show that an increase in the radiation parameter decreases the local skin friction parameter and increases the local heat transfer parameter. Cortell (2010) have highlighted the effect of the internal heat generation and radiation on a certain free convection flow. (Olanrewaju et al., 2011) have examined the effects of internal heat generation, thermal radiation, and buoyancy force on a boundary layer over a vertical plate with a convective surface boundary condition. The

${ }^{\dagger}$ Corresponding author. Email: elyazid_flilihi@yahoo.fr 
non-linear equations governing the flow were solved numerically using a shooting technique together with a sixth-order Runge-Kutta integration scheme.On the other hand, the radiation flux and internal heat source effects on free convection over some geometries have been examined by Rahman (2010); Ferdows et al. (2011); Elbashbeshy et al. (2016). These authors found that, the radiation flux promotes more the friction forces and significantly affect the heat transfer rate at the wall. Subsequently, (Salleh et al., 2012) have presented the effect of radiation free convection boundary layer flow over a permeable horizontal flat plate embedded in a porous medium with mixed thermal boundary conditions.

Recently, (Alkasasbeh et al., 2015) studied the effect of radiation and magnetohydrodynamic free convection boundary layer flow on a solid sphere with convective boundary conditions. The basic equations of the boundary layer are transformed into a non-dimensional form and reduced to nonlinear systems of partial differential equations and solved numerically using an implicit finite difference scheme known as the Keller-box method. These authors showed that, when the magnetic parameter and the conjugate parameter for the convective boundary conditions are fixed, the increasing of the radiation parameter, leads to increase the local Nusselt number and the local skin friction coefficient.

Very recently, (Ferdows and Liu, 2016) have analyzed the steadystate boundary layer flow with free convective heat transfer over a horizontal surface embedded in a fluid-saturated porous medium subject to variable wall heat flux (WHF) and variable wall temperature (VWT). It is found that the flow profiles along with physical parameters significantly altered the rate of heat transfer and induced more flow within the boundary layer than that of without IHG.

The papers of Achemlal et al. (2013) and Guedda et al. (2014) investigated the free convection over a vertical flat plate embedded in saturated a Darcy porous medium with a variable heat source and radiation flux. The present paper is an extension of the work of (Achemlal et al., 2013) to Darcy-Brinkman model, taking into account the convective term. This study finds applications in the fields of petroleum engineering, geothermal energy, etc.

\section{MATHEMATICAL FORMULATION AND RESOLUTION METHOD}

In this problem, the steady free convection heat transfer from a multioriented isothermal plate embedded in a non-Darcian porous medium saturated by a Newtonian fluid with internal heat generation and radiation effects is considered. An angle makes to determine the position of the plate relative to the vertical direction. The $\mathrm{x}$-axis is taken along the plate and y-axis is normal to it. The plate of length $H$ is maintained at a uniform temperature $T_{w}, T_{\infty}$ and is the temperature of the fluid away from the plate assumed constant. The Darcy-Brinkman model is used to describe the flow in porous medium taking into account the convective term in momentum equation. Here, it is assumed that the porous medium is isotropic and homogeneous, that all properties of the fluid and porous medium are constant, except the influence of density variation in the body force term, under the Boussinesq approximation.. The convective fluid and the porous medium are in local thermodynamic equilibrium anywhere. The flow is supposed two-dimensional, stationary and laminar for an incompressible fluid. The radiation heat flux in the $\mathrm{x}$-direction is considered negligible in comparison to the y-direction. The physical model and coordinate system are shown in the Fig. 1.

Under the Boussinesq approximation and taking into account the above mentioned assumptions. The governing equations describing the problem can be written as follows:

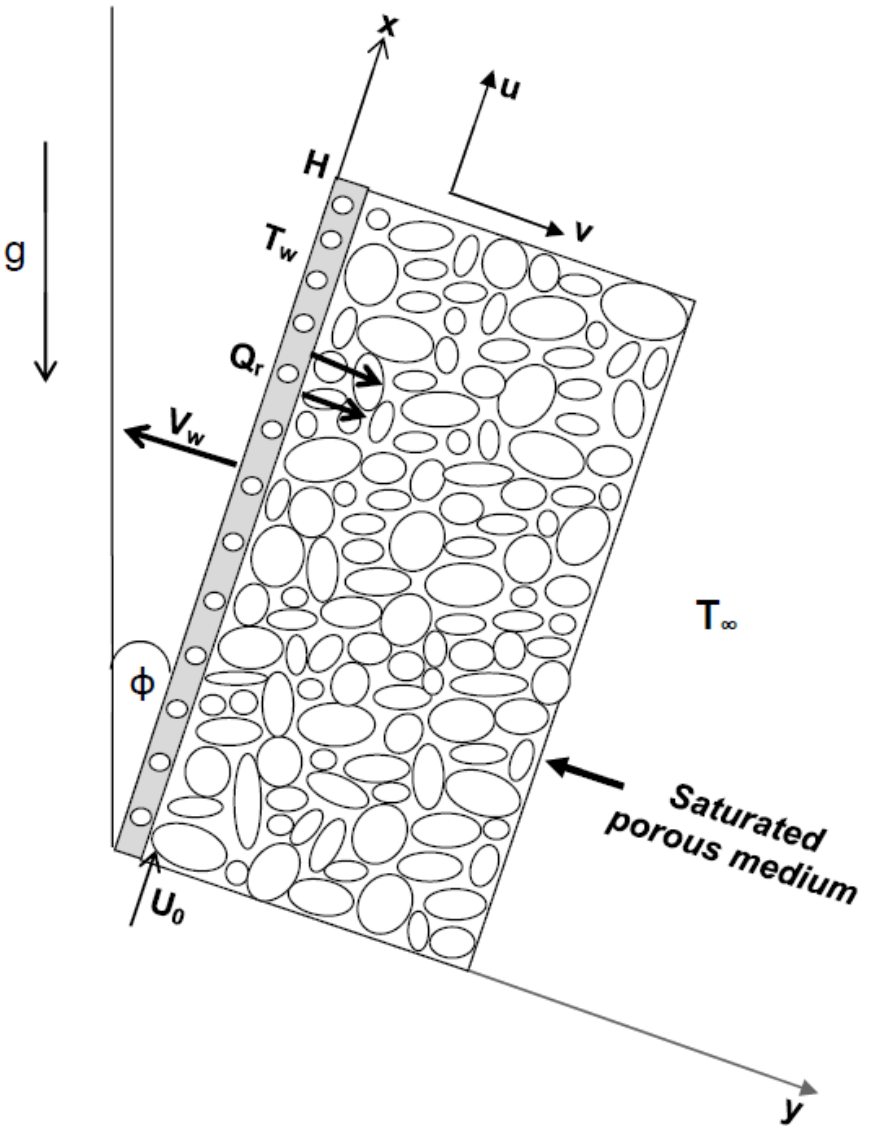

Fig. 1 Physical model and coordinate system.

$$
\left\{\begin{array}{l}
\frac{\partial u}{\partial x}+\frac{\partial v}{\partial y}=0 \\
u \frac{\partial u}{\partial x}+v \frac{\partial u}{\partial y}=\nu \frac{\partial^{2} u}{\partial y^{2}}+g \beta\left(T-T_{\infty}\right) \cos \phi-\frac{\nu}{K^{\prime}} u \\
u \frac{\partial T}{\partial x}+v \frac{\partial T}{\partial y}=\alpha \frac{\partial}{\partial y}\left(\frac{\partial T}{\partial y}-\frac{Q_{r}}{k}\right)+q^{\prime \prime \prime}
\end{array}\right.
$$

The associated boundary conditions are given by:

$$
\left\{\begin{array}{l}
y=0, \quad x \geq 0, \quad u=U_{0}, \quad v=V_{w}(x), \quad T=T_{w} \\
y \rightarrow \infty, \quad x \geq 0, \quad u=0, \quad v=0, \quad T \rightarrow T_{\infty}
\end{array}\right.
$$

where $u$ and $v$ are, respectively, the velocity components along $\mathrm{x}$ and $\mathrm{y}$ axes, and $T$ is the temperature of the fluid. The constants $\nu, \alpha, k, g, K^{\prime}$ and $\beta$ are respectively, kinematic viscosity, thermal diffusivity, thermal conductivity, gravitational acceleration, permeability of porous medium and thermal expansion coefficient. $U_{0}$ and $V_{w}=B \cdot x^{-1 / 2}$ are respectively, the uniform velocity parallel to the plate and the velocity of the fluid suction at the plate, where B is a negative constant .

The radiation flux on the basis of the Rosseland diffusion model for radiation heat transfer is expressed as:

$$
Q_{r}=-\frac{16 \sigma^{*} T_{\infty}^{3}}{3 k^{*}} \frac{\partial T}{\partial y}
$$

where $\sigma^{*}$ is the Stefan-Boltzmann constant and $k^{*}$ is the mean absorption coefficient. 
Here an exponential form is used for the internal heat generation, and it is as follows:

$$
q^{\prime \prime \prime}=\frac{U_{0}\left(T_{w}-T_{\infty}\right)}{2 x} e^{-\eta}
$$

Using (3) and (4), the third equation of the system of equations (1) takes the form:

$$
u \frac{\partial T}{\partial x}+v \frac{\partial T}{\partial y}=\alpha \frac{\partial^{2} T}{\partial y^{2}}\left(1+\frac{16 \sigma^{*} T_{\infty}^{3}}{3 k k^{*}}\right)+\frac{U_{0}\left(T_{w}-T_{\infty}\right)}{2 x} e^{-\eta}
$$

The non-linearity of the model and the complexity of the phenomena encountered (boundary layer, instability, geometry of the porous medium ...) make difficult its resolution direct. The transformation of the PDE system, describing the problem studied in a set of non-linear differential equation becomes indispensable. So, we apply the following similarity transformations:

$$
\eta=y \sqrt{\frac{U_{0}}{2 \nu x}}, \quad \psi=\left(2 \nu x U_{0}\right)^{1 / 2} f(\eta), \quad \theta=\frac{T-T_{\infty}}{T_{w}-T_{\infty}}
$$

where $\psi$ is the stream function defined in the usual notation $u=\frac{\partial \psi}{\partial y}$, $v=-\frac{\partial \psi}{\partial x} . f$ and $\theta$ are the dimensionless similarity functions.

After substitution and development the governing equations (1), (2) and (5) gives rise to the following system of ordinary differential equations:

$$
\left\{\begin{array}{l}
f^{\prime \prime \prime}+f f^{\prime \prime}+G r \theta \cos \phi-K f^{\prime}=0 \\
\left(3+\frac{4}{R}\right) \theta^{\prime \prime}+3 \operatorname{Pr} f \theta^{\prime}+3 \operatorname{Pr} e^{-\eta}=0
\end{array}\right.
$$

where $G r=\frac{g \beta\left(T_{w}-T_{\infty}\right) 2 x}{U_{0}^{2}}$ is the Grashof number, $K=\frac{2 \nu x}{K^{\prime} U_{0}}$ is the permeability parameter, $\operatorname{Pr}=\frac{\nu}{\alpha}$ is the Prandtl number and $R=$ $\frac{k k^{*}}{4 \sigma^{*} T_{\infty}^{3}}$ is the radiation parameter.

The transformed boundary conditions for equations (2) are:

$$
\left\{\begin{array}{l}
\eta=0, f(0)=f_{w}, f^{\prime}(0)=1 \\
\eta \rightarrow \infty, f^{\prime}(\infty)=0, \theta(\infty)=0
\end{array}\right.
$$

where $f_{w}=-V_{w} \sqrt{\frac{2 x}{\nu U_{0}}}$ is the suction parameter.

The system of the ordinary differential equations (7) with the boundary conditions (8) are solved numerically by using the fifth-order RungeKutta scheme associated with the shooting method.

\section{SKIN FRICTION COEFFICIENT AND NUSSELT NUMBER}

The physical quantities of most interest in such problems are the local skin friction coefficient $C_{f}$ and local Nusselt number $N u$ which indicate physically wall shear stress and rate of heat transfer, respectively.

The local skin friction coefficient and the local Nusselt number are given, respectively, by the following equations:

$$
C_{f}=\frac{2}{\sqrt{R e}} f^{\prime \prime}(0), \quad N u=-\sqrt{R e} \theta^{\prime}(0)
$$

where $R e=\frac{U_{0} x}{\nu}$ is the Reynolds number.

\section{ANALYSIS RESULTS}

In this study, we have analyzed the effects of the radiation parameter $R$, the inclination angle $\phi$, the suction parameter $f_{w}$, the Grashof number $G r$, the permeability parameter $K$ and the Prandtl number $\operatorname{Pr}$ (ranging between 0.1 and 10) on the free convection flow over an isothermal plate embedded in a non-Darcian porous medium saturated by a Newtonian fluid with internal heat generation. We note that the fluid suction corresponds to $f_{w}>0$, and $R \rightarrow \infty$ corresponds to the absence of the thermal radiation.

To assess the accuracy of our results, the comparisons are made with (Ferdows et al., 2011) results in term of local Nusselt number with various values of Prandtl number at $G r=2, R=1, K=1, f_{w}=1$ and $\phi=30$ degree are presented in Table 1 , showing a very good agreement.

Table $1 N u / R e^{1 / 2}$ for various values of $\operatorname{Pr}$ at $G r=2, R=1, K=1$, $f_{w}=1$ and $\phi=30$ degree.

\begin{tabular}{|c|c|c|c|}
\hline$P r$ & Ferdows et al, (2011) & Present study & Relative error (\%) \\
\hline 0.71 & 0.3004 & 0.2990 & 0.47 \\
\hline 2.05 & 0.5431 & 0.5410 & 0.39 \\
\hline 4.24 & 0.8760 & 0.8710 & 0.57 \\
\hline 13.6 & 2.1396 & 2.1300 & 0.45 \\
\hline
\end{tabular}

\subsection{Isothermal Lines}

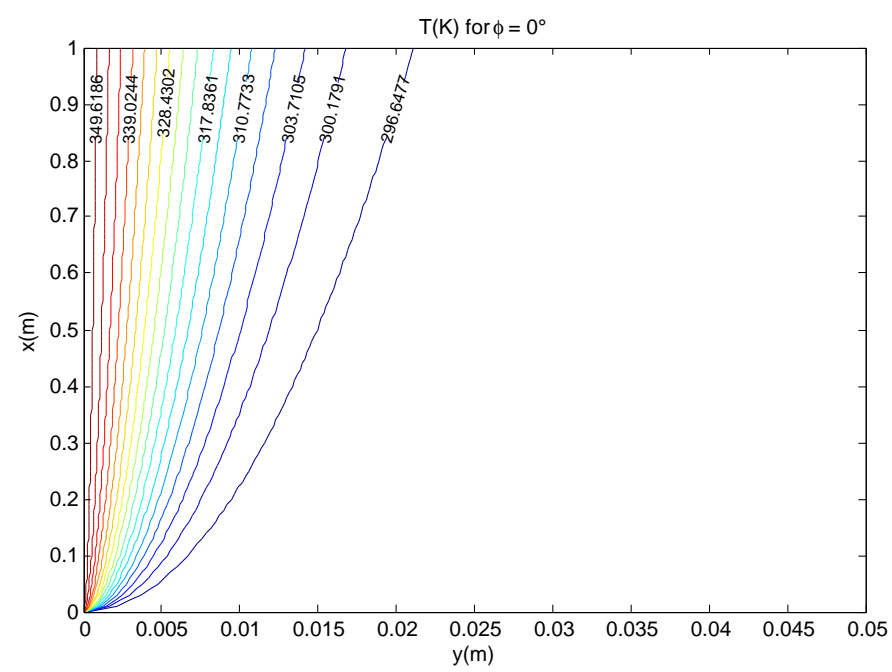

Fig. 2 Isothermal lines according to $\mathrm{x}$ and $\mathrm{y}$ at $\phi=0$ degree.

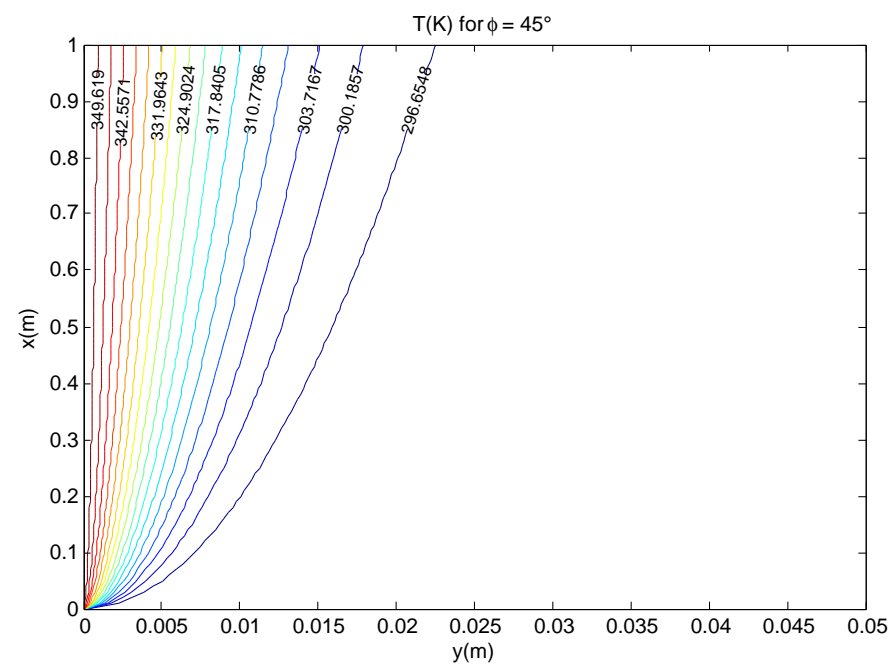

Fig. 3 Isothermal lines according to $\mathrm{x}$ and $\mathrm{y}$ at $\phi=45$ degree. 
Figures 2, 3 and 4 show the isothermal lines distributions in the boundary layer area of an isothermal $\left(T_{w}=353.15 \mathrm{~K}\right)$ and permeable plate placed in a saturated porous medium $\left(T_{\infty}=293.15 K\right)$, for three position of the plate: vertical, inclined and horizontal corresponding respectively to $\phi=0$ degree, $\phi=45$ degree and $\phi=90$ degree at $G r=2, \operatorname{Pr}=0.71, R=1, K=1$ and $f_{w}=1$. From these figures, it is observed that, passing from the vertical to the horizontal position of the plate, more the heat is transferred to the porous medium, which leads to the widening of the thermal boundary layer thickness. Consequently, in the field of petroleum extraction by the thermal method, the vertical position of the used equipment is the most suitable for optimum oil extraction (high trasfert rate).

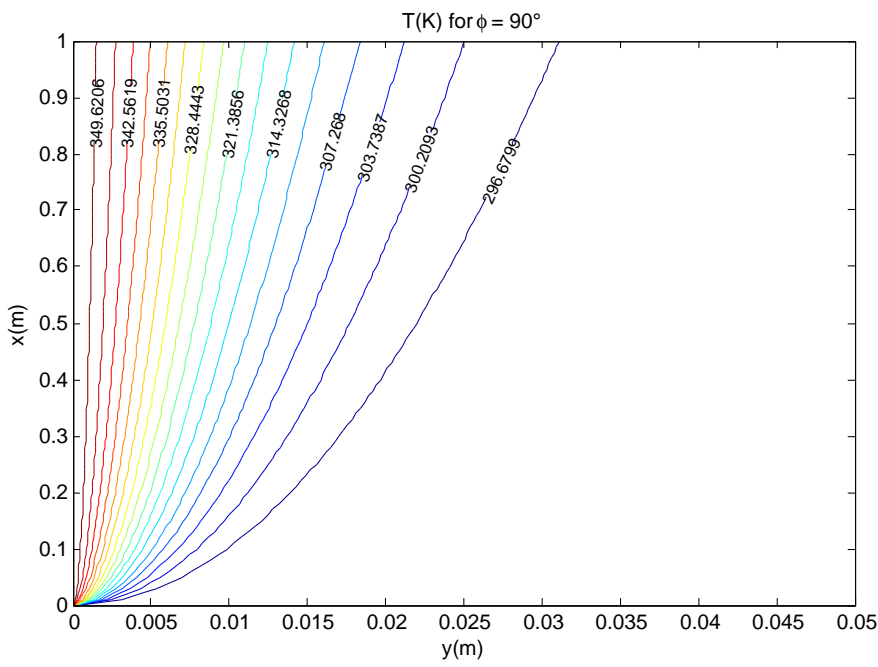

Fig. 4 Isothermal lines according to $\mathrm{x}$ and $\mathrm{y}$ at $\phi=90$ degree.

Figures 5 and 6 illustrate for $G r=2, \operatorname{Pr}=0.71, K=1$ and $f_{w}=1$, the isothermal lines distributions in the boundary layer area of an isothermal $(\mathrm{Tw}=353.15 \mathrm{~K})$ and permeable inclined plate $\phi=30$ degree placed in a saturated porous medium $\left(T_{\infty}=293.15 K\right)$, for selected values of the radiation parameter $R=0.5$ and $R=10^{6}$ respectively. Here, it is clearly remarkable that the taking into account of the thermal radiation favors the thermal transfer to the porous medium, which leads to the expansion of the thermal boundary layer. Which shows that it is unreasonable to neglect the radiation effect especially in applications requiring medium or high temperatures.

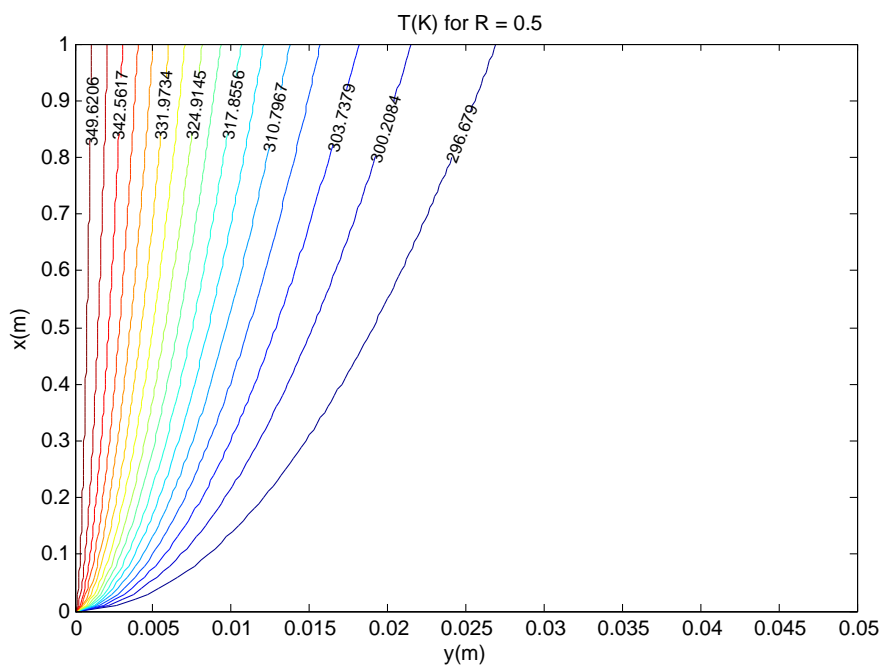

Fig. 5 Isothermal lines according to $\mathrm{x}$ and $\mathrm{y}$ at $R=0.5$.

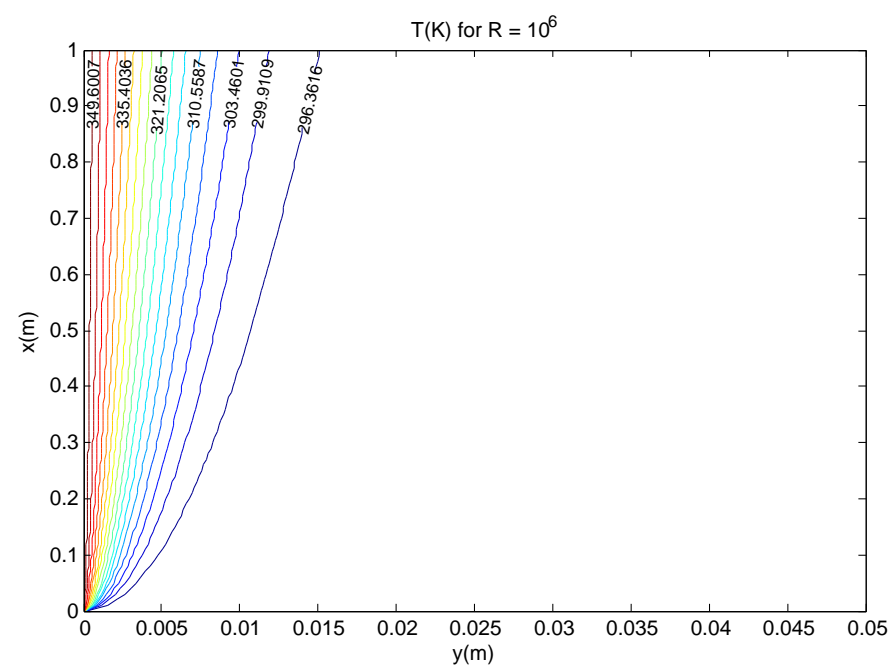

Fig. 6 Isothermal lines according to $\mathrm{x}$ and $\mathrm{y}$ at $R=10^{6}$.

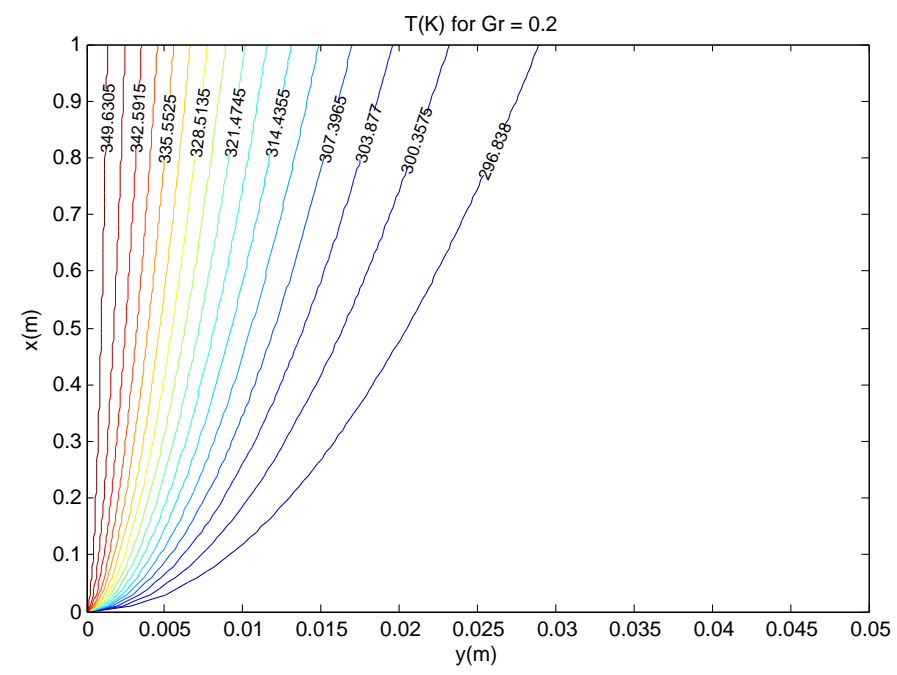

Fig. 7 Isothermal lines according to $\mathrm{x}$ and $\mathrm{y}$ at $G r=0.2$.

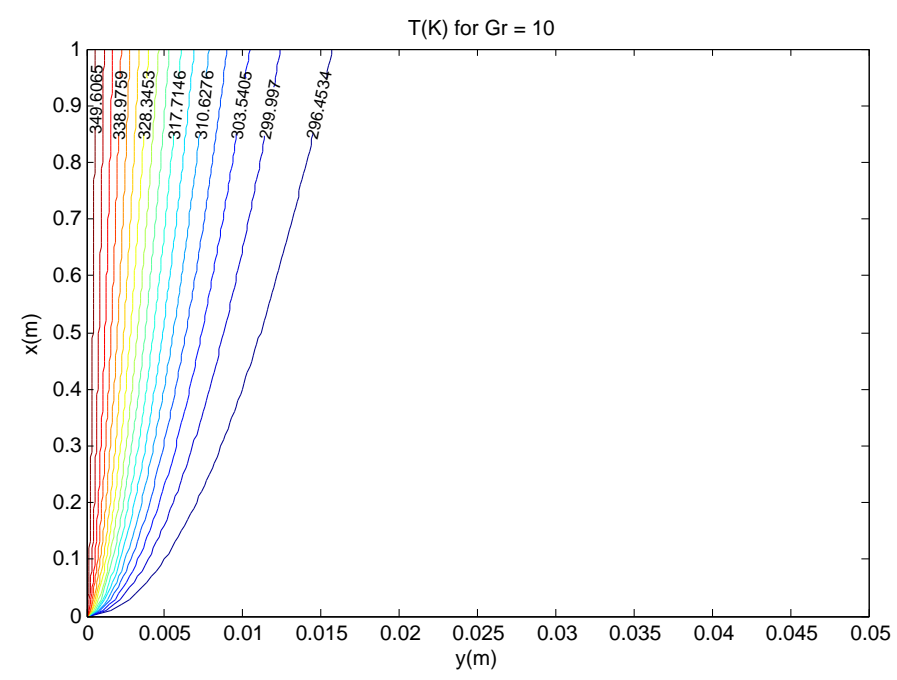

Fig. 8 Isothermal lines according to $\mathrm{x}$ and $\mathrm{y}$ at $G r=10$.

Figures 7 and 8 depict for $\operatorname{Pr}=0.71, R=1, k=1$ and $f_{w}=1$, the isothermal lines distributions in the boundary layer area of an isother- 
$\mathrm{mal}(\mathrm{Tw}=353.15 \mathrm{~K})$ and permeable inclined plate $\phi=30$ degree placed in a saturated porous medium $\left(T_{\infty}=293.15 K\right)$, for selected values of the Grashof number $G r=0.2$ and $G r=10$ respectively. From this figures, it is noteworthy clearly that the temperature decreases with increasing the Grashof number $G r$, and consequently leads to reduces the thermal boundary layer thickness. This can be justified by the importance of the buoyancy forces which lead to a fast cooling around the plate.

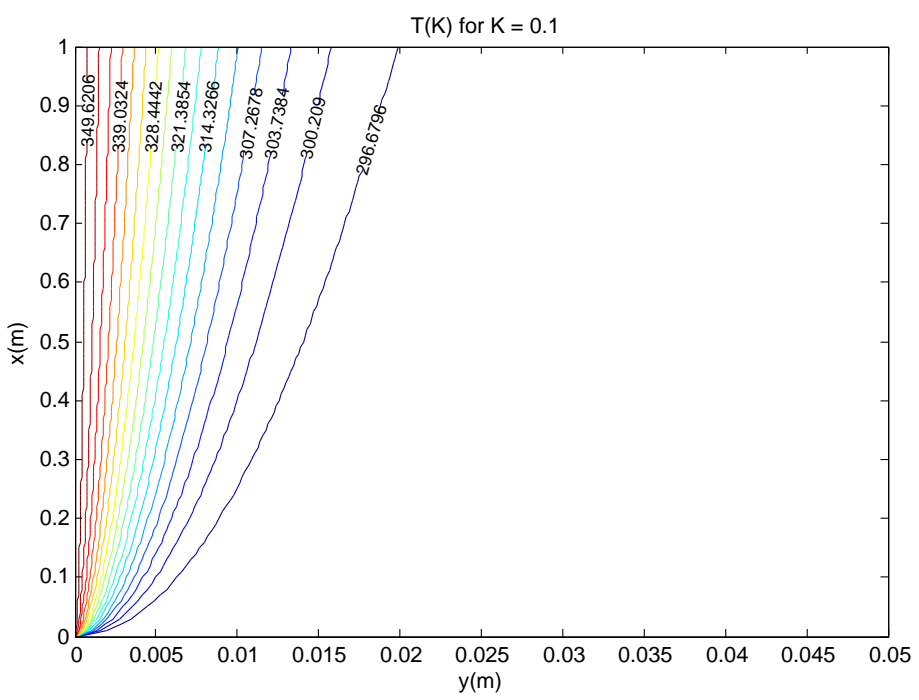

Fig. 9 Isothermal lines according to $\mathrm{x}$ and $\mathrm{y}$ at $K=0.1$.

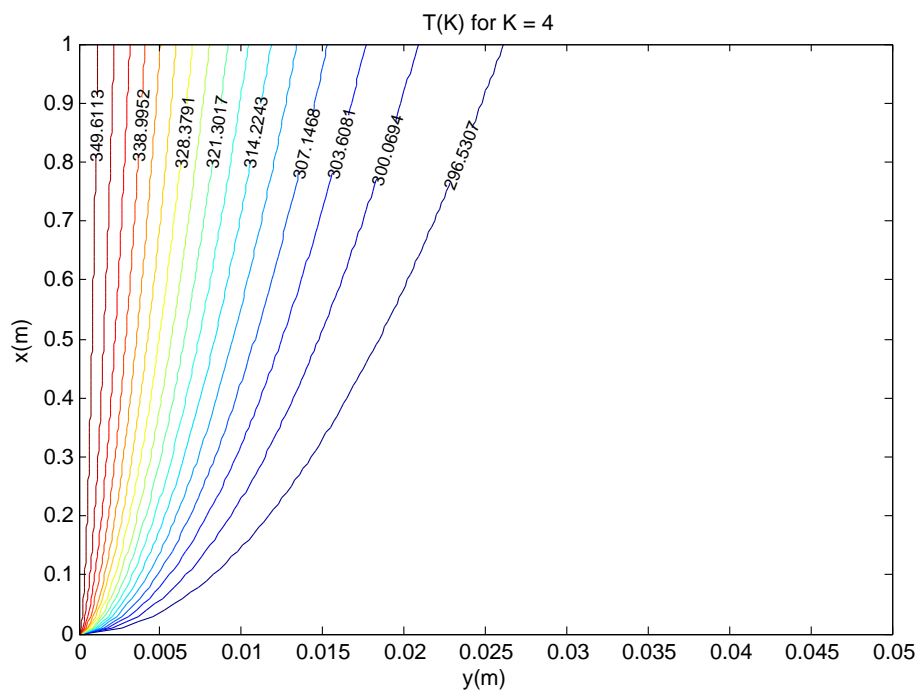

Fig. 10 Isothermal lines according to $\mathrm{x}$ and $\mathrm{y}$ at $K=4$.

Figures 9 and 10 show for $G r=2, \operatorname{Pr}=0.71, R=1$ and $f_{w}=1$, the isothermal lines distributions in the boundary layer area of an isothermal $(\mathrm{Tw}=353.15 \mathrm{~K})$ and permeable inclined plate $\phi=30$ degree placed in a saturated porous medium $\left(T_{\infty}=293.15 K\right)$, for selected values of the permeability parameter $K=0.1$ and $K=4$, respectively. From these figures, it can be deduced that the more permeable porous medium allows to diffuse more the heat away of the plate, which explains the notable widening in the thermal boundary layer thickness, unlike to the case where the porous medium is less permeable.

\subsection{Local Heat Transfer Rate and Skin Friction Profiles}

Figures 11 and 12 illustrate the heat transfer rate and skin friction at the wall according to the inclination angle $\phi$ for an isothermal and permeable plate in a saturated porous medium with an internal heat generation for various values of the radiation parameter $R$ at $G r=2, P r=0.71$, and $K=1$. From these figures, it is observed that, for all values of $R$, the heat transfer rate, and the skin friction decrease with the increase in the angle of inclination. Here, it's obvious that the heat transfer rate and skin friction are more important at the wall in the case where the plate is vertical. We notice also that the radiation effect leads to reduce the heat transfer rate and increases the shear stress at the wall.

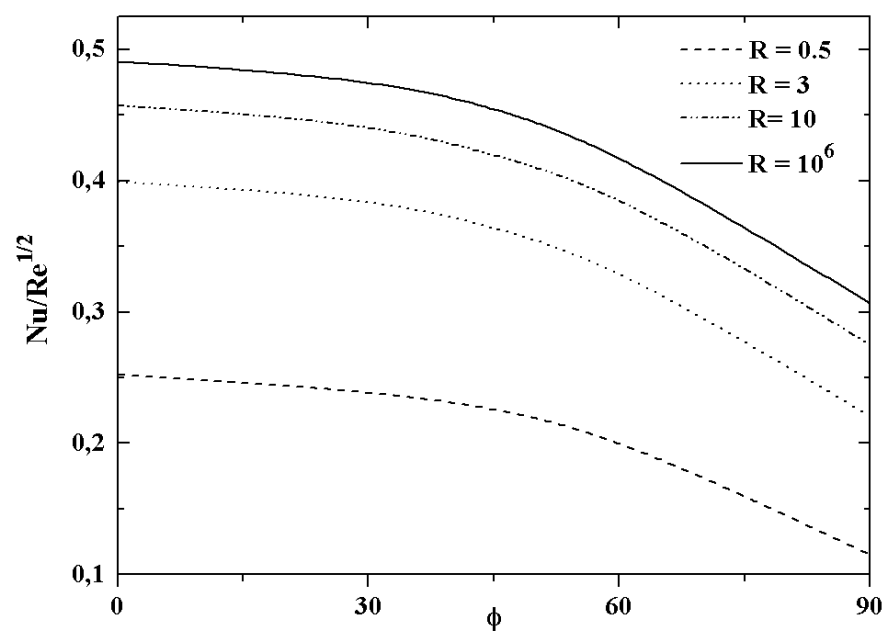

Fig. 11 Nusselt number profiles versus $\phi$ for various values of R.

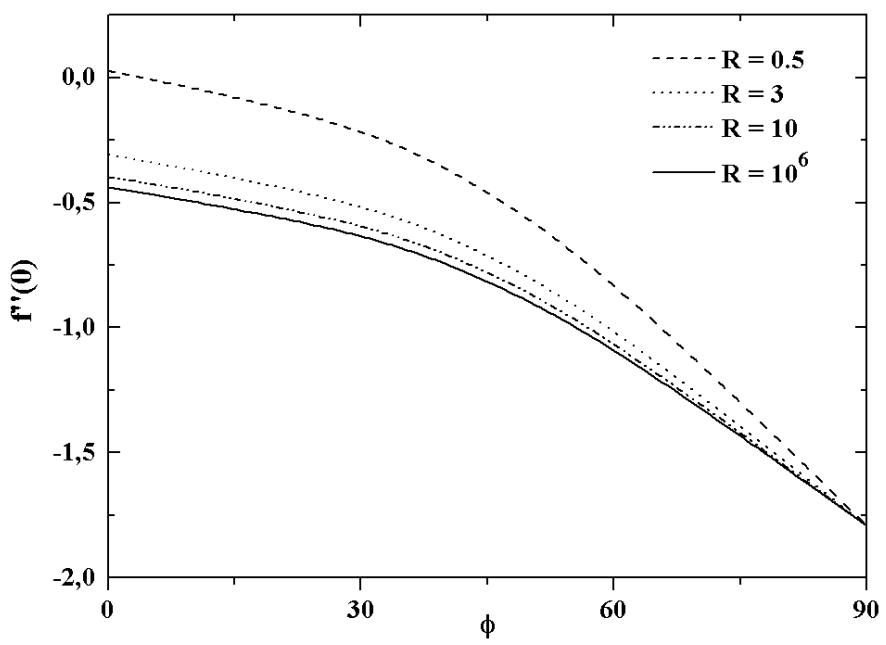

Fig. 12 Dimensionless shear stress profiles versus $\phi$ for various values of $\mathrm{R}$.

The effects of the Grashof number and fluid suction on the wall heat transfer rate and skin friction at $\operatorname{Pr}=0.71, R=1, K=1$ for an inclined isothermal plate ( $\phi=30$ degree) embedded in a saturated porous medium in the presence of an internal heat generation, are plotted, respectively, in figures 13 and 14. Here, we notice also that the buoyancy forces amplified the heat transfer rate and friction forces at the wall for all values of the suction parameter . Moreover, it's important to notice that the fluid suction at the plate surface makes to amplify the heat transfer rate and to reduce the effect of the shear forces at the wall. 


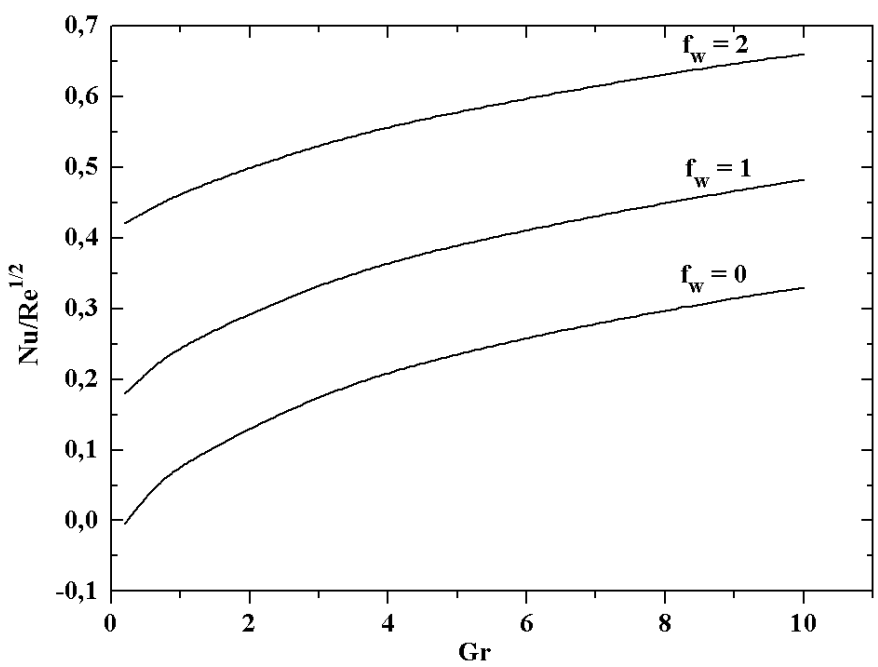

Fig. 13 Nusselt number profiles versus Gr for selected values of the suction parameter $f_{w}$.

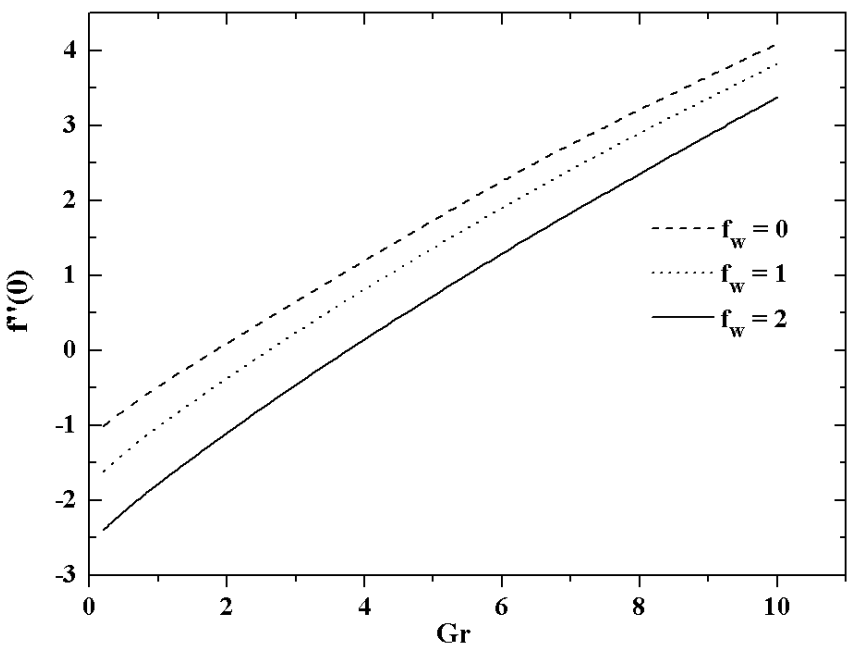

Fig. 14 Dimensionless shear stress profiles versus $G r$ for selected values of the suction parameter $f_{w}$.

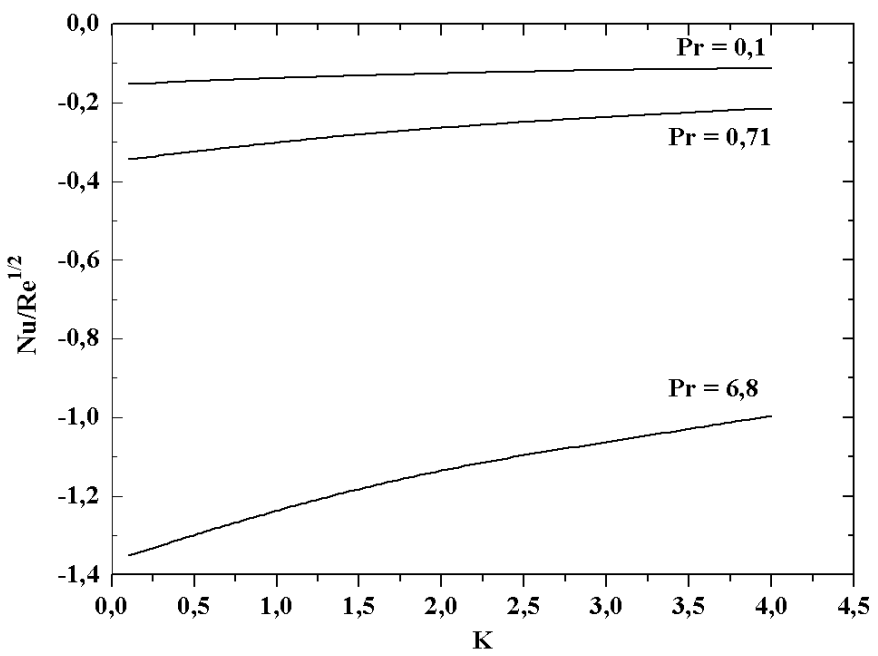

Fig. 15 Nusselt number profiles versus $K$ for selected values of the Prandtl number $P r$.

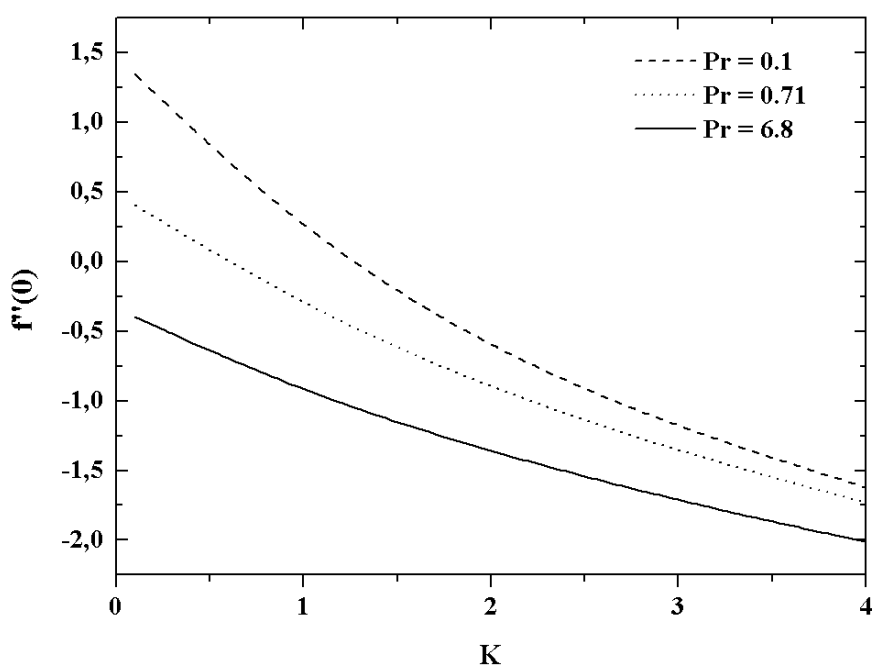

Fig. 16 Dimensionless shear stress profiles versus $K$ for selected values of the Prandtl number $\mathrm{Pr}$.

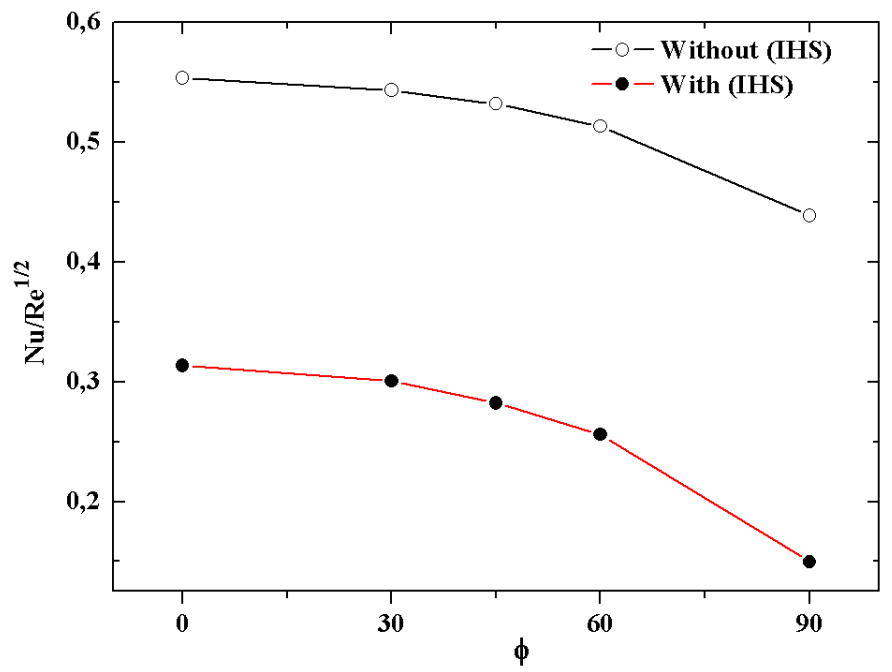

Fig. 17 Nusselt number profiles versus $\phi$ with and without IHS.

Figures 15 and 16 show, respectively, for $G r=2, R=1, \phi=30$ degree and $f_{w}=1$ the Nusselt number and the shear stress profiles at the wall as function of the permeability parameter $K$ for some values of the Prandtl number $\mathrm{Pr}$. Here, we notice that the heat transfer rate increases and the shear stress decreases at the wall with increasing of the permeability parameter $K$ independently of the Prandtl number $\mathrm{Pr}$. In addition, the heat transfer rate and friction forces at the wall increase when the thermal profile is faster than the hydrodynamic profile $\operatorname{Pr}<1$ unlike the case where $\operatorname{Pr}>1$.

In figures 17 and 18, we present, respectively, the evolution of the Nusselt number and the shear stress at the wall for several positions of the plate at $G r=2, \operatorname{Pr}=0.71, R=1, K=1$ and $f_{w}=1$ with and without internal heat source. From these figures, it's concluded that the presence of a variable source of energy in the medium (joule effect, source of hot water, etc.) makes to reduce the heat transfer rate and to amplify the shear forces at the surface for all selected positions of the plate. 


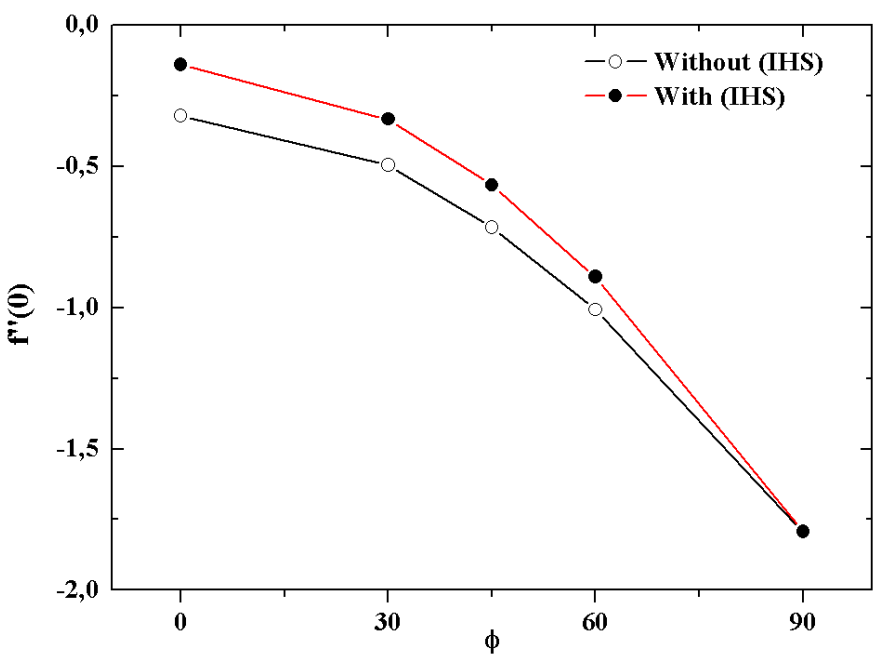

Fig. 18 Shear stress profiles versus $\phi$ with and without IHS.

\section{CONCLUSIONS}

A numerical investigation has been made for a steady thermal convection currents around a multi-oriented plate embedded in Darcy-Brinkman porous medium taking into account a variable internal heat generation and radiation flux. Compared to the cited works, we have discussed further the influence of the physical parameters on heat transfer rate and friction at the surface, in particular the effects of plate orientation, thermal radiation and heat source term. In addition, we have illustrated these effects on the thermal and dynamic profiles as a function of the dimensional variables $\mathrm{x}$ and $\mathrm{y}$. The following main conclusions can be drawn from the present study:

- The thermal radiation promotes more the heat transfer to the porous medium, and leads to the expansion of the thermal boundary layer.

- The importance of the buoyancy forces leads to a rapid cooling around the plate, and reduces the thermal boundary layer thickness.

- The more the porous medium is permeable, the more the heat is transferred away of the plate.

- The fluid suction at plate surface makes to amplify the heat transfer rate and to reduce the effect of the shear forces at the wall.

- The wall heat transfer rate is optimal for the case where the plate is vertical.

- The variable heat source reduces the heat transfer rate and amplify the shear forces at the wall.

\section{NOMENCLATURE}

$C_{f} \quad$ skin friction coefficient

$f \quad$ dimensionless function

$f_{w} \quad$ suction parameter

$g \quad$ gravitational acceleration $\left(\mathrm{m} / \mathrm{s}^{2}\right)$

Gr Grashof number

$H \quad$ the plate length (m)

$k \quad$ thermal conductivity $(\mathrm{W} / \mathrm{m} \cdot \mathrm{K})$

$k^{*} \quad$ the mean absorption coefficient

$K^{\prime} \quad$ permeability of porous medium

$K \quad$ permeability parameter

$\mathrm{Nu} \quad$ Nusselt number

$\operatorname{Pr} \quad$ Prandtl number

$Q_{r} \quad$ radiation flux

$q^{\prime \prime \prime} \quad$ internal heat generation

$R \quad$ radiation parameter

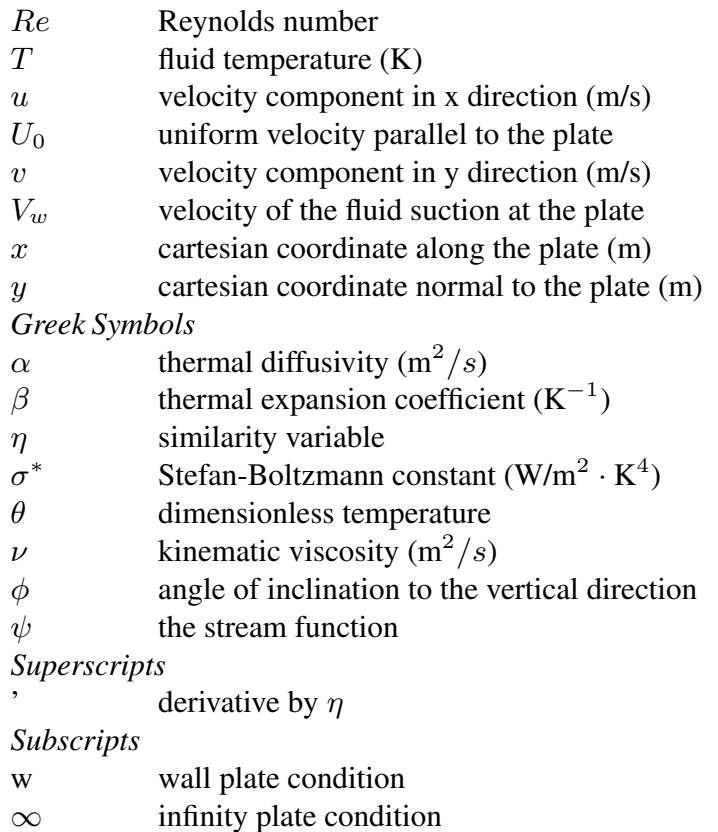

\section{REFERENCES}

Achemlal, D., Sriti, M., El Haroui, M., and Guedda, M., 2013, "Free convection modeling over a vertical flat plate embedded in saturated porous medium with a variable heat source and radiation flux," World Journal of Modelling and Simulation, 9, 163-172.

Alkasasbeh, H., Salleh, M., Tahar, R., Nazar, R., and Pop, I., 2015, "Effect of radiation and magnetohydrodynamic free convection boundary layer flow on a solid sphere with convective boundary conditions," Walailak J Sci\& Tech, 12, 849-861.

Aydin, O., and Kaya, A., 2008, "Radiation effect on MHD mixed convection flow about a permeable vertical plate," Heat Mass Transfer, 45, 239-246.

http://dx.doi.org/10.1007/s00231-008-0428-y.

Chamkha, A.J., Camille, I.B., and Khanafer, K., 2002, "Natural convection from an inclined plate embedded in a variable porosity porous media due to solar radiation," Int J Therm Sci, 41(4), 73-81. http://dx.doi.org/10.1016/S0735-1933(98)00016-5.

Cortell, R., 2010, "Internal heat generation and radiation effects on a certain free convection flow," Int Journal of Nonlinear Science, 9, 468-479.

Elbashbeshy, E.M.A., Emam, T.G., and Sayed, E.A., 2016, "Effect of thermal radiation on free convection flow and heat transfer over a truncated cone in the presence of pressure work and heat generation / absorption," Thermal Science, 9(2), 555-565. http://dx.doi.org/10.2298/TSCI130409006E.

Ferdows, M., and Liu, D., 2016, "Inertia effect on free convection over horizontal surface in a porous medium with a variable wall heat flux and variable wall temperature containing Internal heat generation," $J$ Phys Math, 7(2).

https://dx.doi.org/10.4172/2090-0902.1000165.

Ferdows, M., Postelnecu, A., and Sivasankaran, S., 2011, "Radiation effects on natural convection in an inclined Porous Surface with internal heat generation," World Applied Sciences Journal, 13, 957-961.

Guedda, M., Sriti, M., and Achemlal, D., 2014, "Natural convection on a vertical plate in a saturated porous medium with internal heat generation," Eur Phys J Plus, 129, 1-13.

https://dx.doi.org/10.1140/epjp/i2014-14170-7. 
Hossain, M.A., and Pop, I., 1997, "Radiation effect on darcy convection flow along an inclined surface placed in porous media," Heat Mass Transfert, 32(4), 223-227.

http://dx.doi.org/10.1007/s002310050115.

Nield, D.A., and Bejan, A., 2006, Convection in porous media, 3rd ed., Springer Science, New York - USA.

PMCid:PMC4092590.

Olanrewaju, P.O., Gbadeyan, J.A., Hayat, T., and Hendi, A.A., 2011, "Effects of internal heat generation, thermal radiation and buoyancy force on a boundary layer over a vertical plate with a convective surface boundary condition," South African Journal of Science, 107(i9/10), art.476-6 pages.

http://dx.doi.org/10.4102/sajs.v107i9/10.476.

Rahman, M.M., 2010, "Radiative heat transfer flow in a porous medium: effects of internal heat generation, mass flux and convective boundary condition," Proceedings of ICAMMM 2010, Sultan Qaboos University.

Raptis, A., 1998, "Radiation and free convection flow through a porous medium," Int comm Heat Mass Transfer, 25, 289-295.

http://dx.doi.org/10.1016/S0735-1933(98)00016-5.

Salleh, M.Z., Najihah, M., Roziena, K., Khasi'ie, N., Nazar, R., and Pop, I., 2012, "Free convection over a permeable horizontal flat plate embedded in a porous medium with radiation effects and mixed thermal boundary conditions," J Math Stat, 8, 122-128.

http://dx.doi.org/10.3844/jmssp.2012.122.128.

Vafai, K., 2005, Handbook of porous media, 2nd ed., CCR Press Taylor\&Francis Group LLC, Boca Raton -USA. 